\title{
Factors that influence the teaching use of Wikipedia in Higher Education
}

\author{
Antoni Meseguer-Artola, Eduard Aibar, Josep Lladós, Julià Minguillón, Maura Lerga \\ Internet Interdisciplinary Institute, Universitat Oberta de Catalunya UOC \\ Av. Tibidabo 39-43, 08035 Barcelona, Spain \\ Tel. +34932542110/ Fax +34934176495 \\ \{ameseguer@uoc.edu, eaibar@uoc.edu, jlladosm@uoc.edu, jminguillona@uoc.edu, mlergaf@uoc.edu\}
}

\begin{abstract}
A key impact the Internet is having on university teaching involves the new choices being provided because of open educational content. Wikipedia is a clear example of these new options. Not only is it a gigantic open repository of knowledge and information, it can also be considered a technological platform that facilitates collaboration for knowledge creation and dissemination.
\end{abstract}

Our research objective is to understand what the main factors are that influence the teaching uses of Wikipedia among university faculty. Based on a Technology Acceptance Model, and using data from an online survey sent to all faculty members of the Universitat Oberta de Catalunya, we analyze the relationships within the internal and external constructs of the model.

We found that both the perception of colleagues' opinion about Wikipedia and the perceived quality of the information in Wikipedia play a central role in our model. These two constructs have a significant direct impact on the perceived usefulness of Wikipedia. This perceived usefulness affects, mediated by the behavioral intention of using Wikipedia, the effective use behavior of the encyclopedia. The degree to which an individual considers it is important to participate in open collaborative environments and the 2.0 profile of the faculty members also play an important role in our model. 


\section{Introduction}

The so-called movement for Open Educational Resources originated in 2001 when MIT launched its OpenCourseWare (OCW) project. In a few years, this initiative spurred many other universities to contribute to the movement by making course materials, study guides, collections of exercises etc. fully accessible to everybody on the network. The vast availability of open educational content is, without question, one of the greatest impacts the Internet is having on university education.

On the other hand, the emergence of Web 2.0 has also opened up a wide range of new possibilities that could end up influencing decisively in learning processes. Wikipedia represents the junction where these two trends converge. From one perspective, it can be depicted as a vast open virtual repository for knowledge and information, with great potential for use in learning processes. And, from another, it has become a prime example of collective construction of knowledge, through a virtual platform that facilitates collaboration on an unprecedented scale.

Nevertheless, though it is widely known that Wikipedia is one of the most employed resources by students, who use it regularly as a reference tool to carry out different assignments and tasks (Wannemacher \& Schulenburg, 2010), the attitude of university faculty does not seem so positive (Dooley, 2010). It is true that an increasing number of professors from many universities around the world are using Wikipedia as a teaching tool (often involving students in editing or creating articles), but they are still a clear minority within university faculty. The aim of our research is to understand what the main factors are that influence the teaching uses of Wikipedia among university faculty. For that purpose we have conducted an online survey delivered to all faculty members of the Universitat Oberta de Catalunya.

This paper is structured as follows. First, we present our analytical model and all the variables used. Next, we introduce our research hypotheses and their link to previous studies. Then the research methodology is presented, and the analysis of the results obtained from the model estimation is shown and commented upon. Finally, we summarize the main conclusions of this paper.

\section{Conceptual model}

Many theoretical models have come about because of research into information technologies' adoption (Venkatesh, Morris, Davis, \& Davis, 2003). As Bagozzi, Davis, and Warshaw (1992) note, TAM (Technology Acceptance Model) is an information systems theory that is widely used for studies into how users (faculty members in this case) adopt and use a particular technology (Wikipedia). And as this paper explores the factors that influence the teaching use of Wikipedia in Higher Education, we use TAM in our analysis as we consider Wikipedia to be a technological platform for knowledge creation and sharing. We are keen to study the relationship (from a utilitarian perspective) between Wikipedia's perceived ease of use and Wikipedia's perceived usefulness. This is both with respect to: (a) the behavioral intention to use it, and, by extension (b) the behavior of actual Wikipedia use.

Today, TAM is one of the leading influential research models that is regularly employed to predict an individual's "intention to use" and "acceptance of new information systems and technologies". Utilizing TAM has helped understanding and explanations of use behavior in information systems' implementation in a great number of areas. In addition, it has provided 
several guidelines within the design of interventions and interfaces that can impact and sway opinion about determinants of use (King \& He, 2006; Lee, Kozar, \& Larsen, 2003).

Because of the ever increasing complexity of information systems and technologies, TAM has garnered extensive attention from information systems' researchers. As a consequence, many studies have suggested that TAM should be enhanced to produce a more inclusive model. It's likely that those studies with a focus on the integration of TAM with Technology Readiness (Lin, Shih, \& Sher, 2007; Godoe \& Johansen, 2012) and TAM with the Theory of Planned Behavior (Chen, Chen, \& Chen, 2009; Lee, 2009) have the most appeal. Because of this, the TAM model has been customized and tweaked for specific cases. Numerous researchers have taken the basis of TAM and added new variables and constructs. Other authors have taken this a step further, and have tailored the definitions for "subjective norms", "job relevance", "image", and "output quality" to reflect the context of higher education institutions. Specific variables have also been created by them to identify situational and individual features.

Out of all major upgrades of TAM, we consider the so called TAM 3 model, where special attention is paid to the external factors that influence the acceptance of a particular technology (Venkatesh \& Bala, 2008). With this approach we are able to study (a) how faculty make a decision about the adoption and use of Wikipedia, and (b) what the external variables and prior factors are that can lead to greater acceptance and effective utilization of Wikipedia.

We selected TAM 3 because this extended version is based on the more comprehensive vision, an element that fulfills our research objectives. A key attraction of TAM3 is its integration of the determinants of perceived usefulness and perceived ease of use. But it does not encompass cross-over effect assumptions. This allowed us to improve the understanding of individual teacher reactions towards Wikipedia in the work environment. And the model lets us consider that experience might affect behavioral intention and the perceived ease of use. So TAM3 is exceptionally suitable because of our interest in looking into the effects of prior experience on use behavior.

The external factors are related with personal characteristics and environmental stimulus. As far as beliefs and attitudes are instrumental in promoting the user acceptance of new information technologies, both types of external variables (individual factors and interpersonal influences) are critical with respect to the process of adopting these innovations. Therefore, we consider both the indirect and the direct effects of these external variables on user's behavior intention.

From the initial set of external variables described in TAM 3, we consider the following 6 factors for the purpose of our research. The definitions, adapted from Chuttur (2009), are shown next to each factor:

- Job relevance: Degree to which an individual perceives the existence of institutional support initiatives that promote the use of open collaborative environments.

- Sharing attitude: Degree to which an individual considers it is important to participate in open collaborative environments.

- Social image: Individual perception of the colleagues' opinion about Wikipedia.

- Profile 2.0: Characterization of an individual as a user of 2.0 tools. 
- Quality of Wikipedia: Perceived quality of the information in Wikipedia.

- Perceived enjoyment: Perception of Wikipedia as a resource of information that can be enjoyed in its own right, aside from any performance consequences resulting from its usage.

Selecting these six constructs allows us to capture the effect of cognitive instruments processes and social influence over behavioral intention and perceived usefulness.

\section{Research hypotheses}

The research hypotheses considered in this paper are exhibited next and drawn in Figure 1. These hypotheses are strongly related with the conceptual model assumed in this research, and focus on the possible relationship within the internal constructs of the TAM model (perceived ease of use of Wikipedia, perceived usefulness of Wikipedia, behavioral intention to use Wikipedia, and Wikipedia use behavior), and between those internal factors and the external latent variables listed in the previous section.

Figure 1: Model graph and hypotheses.

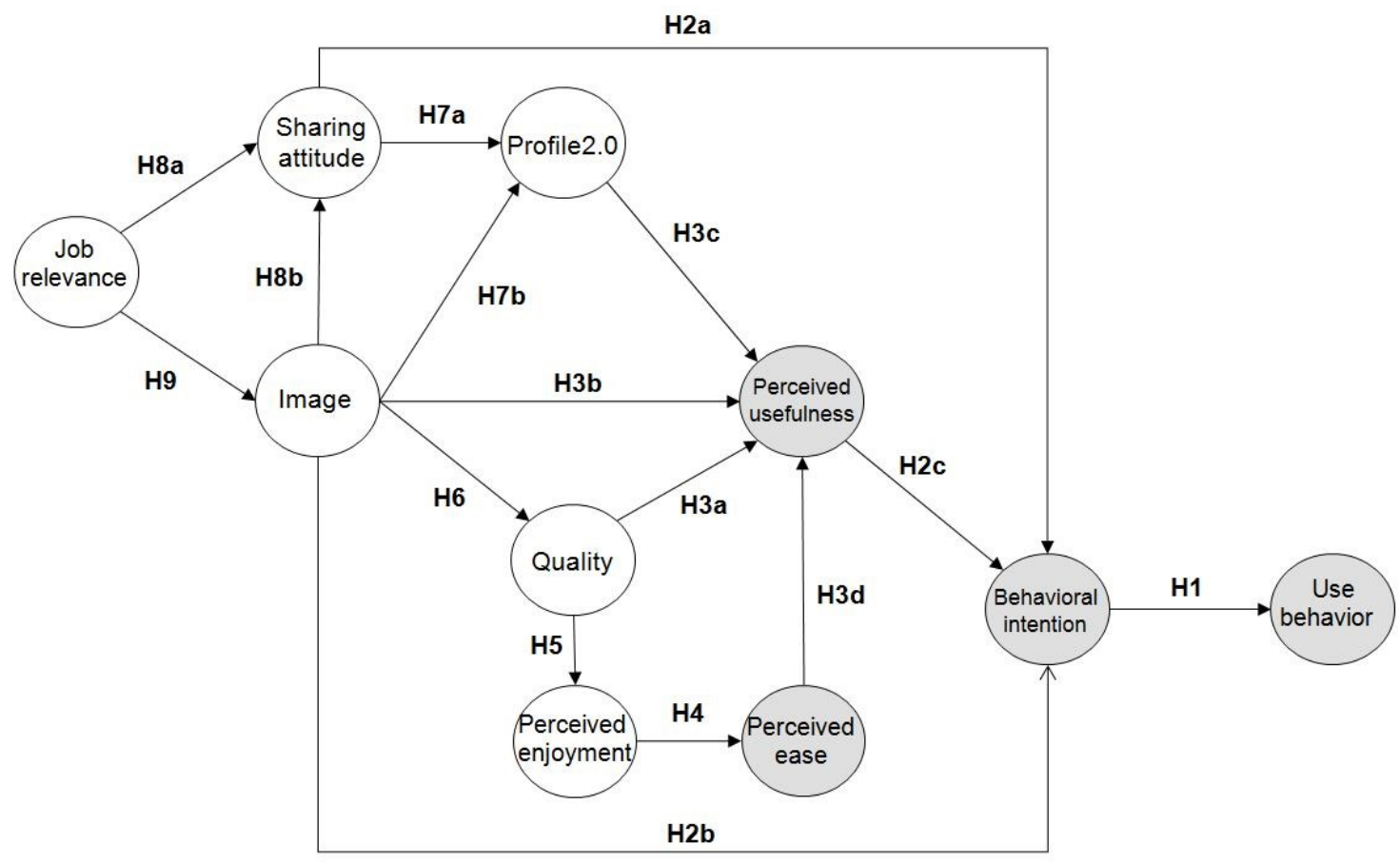

Our first hypothesis has to do with the possible influence of the behavioral intention to use Wikipedia in the effective Wikipedia use behavior. This is a common assumption in the TAM model, and it is considered in most papers dealing with this approach (Venkatesh \& Bala, 2008).

H1: The use behavior of Wikipedia by teachers is determined by their behavioral intention to use it. 
A common assumption in previous studies on faculty use of Wikipedia is that quality, accuracy and reliability are very often the main concerns for most scholars. The overall skeptical view on Wikipedia as a legitimate source of information, usually attributed to faculty members, is thus explained by a negative assessment of its quality. Jaschik (2007), for instance, mentions the lack of a clear and identifiable authorship and, thus, the difficulty to verify articles' content are the main reason for not citing Wikipedia in scholarly papers. Another study based on a survey to faculty members with 105 respondents (Dooley, 2010) finds two main causes of their negative attitude and the very low rate of frequently users: a widespread perception of inaccuracy of its content and also its potential for discouraging students from using other more reliable sources of information.

Contrary to this view, our hypothesis states that the behavioral intention to use Wikipedia in teaching is mostly determined by faculty attitudes towards publishing open resources and getting students to be familiar with collaborative environments (something we have called "sharing attitude"), by the social image of Wikipedia among colleagues, and by their perceived usefulness as a learning resource (both by improving the learning process and by fostering new skills for students).

H2: The behavioral intention of using Wikipedia by teachers is directly influenced by their sharing attitude (H2a), by their perception about the social image of Wikipedia (H2b), and by the perceived usefulness of Wikipedia (H2c).

Since, as stated in the previous hypothesis, the perceived usefulness of Wikipedia for learning purposes is one of the main determinants of its teaching use, we may also ask which factors influence, in its turn, that perception. Wikipedia is, above all, a source of information, so quality should be one of the main elements to take into account. This is also a common result in previous literature. Lack of credibility is identified by H.-L. Chen (2010) as university faculty's main concern about Wikipedia. The possibility of anonymous editing, the absence of formal pre-publication peer review, and the blurred authorship of entries, are also highlighted by Knight \& Pryke (2012) as factors contributing to faculty's negative perception of its usefulness as a teaching tool.

However, our hypothesis adds three other features that have not been considered to be so important in past studies. As in hypothesis 2, we expect the perceived opinion and practices of colleagues to be very relevant. Familiarity with web 2.0 applications is another key element, since wikis are paradigmatic examples of user-generated content sites. Finally, we also posit the perceived ease of use as a fourth determinant.

H3: The perceived quality of Wikipedia $(\mathrm{H} 3 \mathrm{a})$ and its perceived social image $(\mathrm{H} 3 \mathrm{~b})$, together with the teachers' profile $2.0(\mathrm{H} 3 \mathrm{C})$ and the perceived ease of use ( $\mathrm{H} 3 \mathrm{~d})$ ), define the perception of usefulness of Wikipedia.

Based on a survey of 14 university instructors, An \& Williams (2010) identified both educational benefits and major barriers of using 2.0 tools. One of the benefits they mention is the ease of use. In fact, the intensive use of Wikipedia by students (Brox, 2012; Knight \& Pryke, 
2012 ) is not only due to the quality of its articles, but also to the easy access to its content, the hypertext structure that facilitates navigation and the abundance of references and sources, according to Alonso \& García (2013) and Lim (2009).

In our survey, the ease of use has been decomposed in three questions asking for the general usability of the resource, the ease of finding the information sought and the ease of modifying articles. Our hypothesis suggests that there is a causal connection between that utilitarian view and a hedonistic feeling of enjoyment, understood as seeing Wikipedia as an entertaining website as well as a resource that encourages curiosity.

H4: The perceived enjoyment of Wikipedia determines its perceived ease of use.

Our next hypothesis establishes that quality is not only determining the perceived usefulness of the resource, a link we could count as trivial, but also the way users see it as entertaining. This hypothesis implies that the perceived enjoyment of using Wikipedia is influenced by its quality perception.

H5: The perceived quality of Wikipedia affects the perceived enjoyment of the free encyclopedia.

Though most of the studies we have referred to tend to highlight quality as the main issue in explaining faculty attitudes and practices towards Wikipedia, few of them explore how the perception of quality is actually built, implicitly assuming an individual process of accuracy and reliability assessment. Our hypothesis, however, is that quality perception is highly influenced by the social environment. In particular, we expect that two elements play an important role in shaping a scholar's view on Wikipedia quality: what colleagues are seen to think and do about it and the way academic environment is perceived to encourage or avoid the open sharing of teaching resources.

This hypothesis is related to those studies that, beyond specific accuracy and credibility concerns, detect a more fundamental conflict on epistemological and cultural grounds between Wikipedia and academia (Black, 2008; S.-L. Chen, 2010; Eijkman 2010).

H6: The social image of Wikipedia is directly connected with its perceived quality.

Since the use of other 2.0 tools is taken as influencing the perceived usefulness of Wikipedia as a teaching resource $(\mathrm{H} 3)$, we expect that the willingness to use 2.0 tools is determined by the social environment, as defined in $\mathrm{H6}$, and by a more fundamental inclination to share academic resources in open media (including publishing research outputs in sites other than standard scientific journals).

H7: The teachers that have a 2.0 profile are those who have a positive sharing attitude (H7a) and a positive perception of the social image of Wikipedia (H7b). 
We expect the sharing attitude of faculty (as explained above) to be influenced both by the social environment within academia (understood mainly as colleagues' opinions and practices regarding Wikipedia) and also by the institutional recognition and support they got from their university, when working in open platforms like Wikipedia. This support was conceived in our survey as the promotion of open collaborative tools and the recognition of its use as a teaching merit. Along these lines, Bayliss (2013), in searching for the causes of faculty's negative view on Wikipedia, mentions a widespread unenthusiastic attitude toward collaborative knowledge production in academic institutions.

H8: The perception that the University promotes the use of open collaborative environments (H8a), considering this use as a merit, and the perception of the social image of Wikipedia $(\mathbf{H} \mathbf{8 b})$ define the sharing attitude of the teacher.

Our final hypothesis suggests that institutional support is also conditioning faculty perception on colleagues' uses and opinions on Wikipedia: the more they think their own university promotes and acknowledges the use of open collaborative environments, the more they think their colleagues use Wikipedia and the more they consider its use to be appropriate as a teaching tool.

H9: The perceived social image of Wikipedia is directly influenced by the perceived relevance the University defines for the open collaborative environments.

\section{Research methodology}

\section{Data collection}

Data from faculty at the Universitat Oberta de Catalunya (UOC) is used to test the conceptual model. The University has a full online learning model, where the use of teaching resources in the virtual classroom plays a central role. Data was collected through an online survey sent to all full-time and part-time professors (2,128 people) at the University at the end of 2012. We obtained 800 valid responses, which implies an acceptable sampling error of $2.74 \%$ (for $p=q=0.5$, and $\alpha=0.05)$. The questionnaire contained 41 questions.

A first analysis on the characteristics of the respondents shows that $57.3 \%$ were men and their average age was 42.2. They come from different knowledge areas: (Arts and Humanities (20.8\%), Science (5.3\%), Health Sciences (7.0\%), Engineering and Architecture (15.4\%), Law (11.8\%), and Social Sciences (39.6\%); and $43.4 \%$ of them have a PhD. The faculty in the sample averaged 10.4 years of university teaching experience.

\section{Measurement}

The constructs in the model were measured by using different items selected from relevant academic bibliography (Venkatesh \& Bala, 2008). These items were adapted to the particular framework of our research: the use of Wikipedia in a virtual education environment. All items had a 5-point Lykert-type scale, ranging from "strongly disagree" to "strongly agree" (level of 
agreement) or from "never" to "very often" (frequency). Table 1 shows the items associated to each construct.

Table 1: Construct measures.

\begin{tabular}{|c|c|}
\hline Construct & Items \\
\hline Job relevance & $\begin{array}{l}\text { (JR1) My university promotes the use of open collaborative environments in the } \\
\text { Internet } \\
\text { (JR2) My university considers the use of open collaborative environments in the } \\
\text { Internet as a teaching merit }\end{array}$ \\
\hline Sharing attitude & $\begin{array}{l}\text { (SA1) It is important to share academic content in open platforms } \\
\text { (SA2) It is important to publish research results in other media than academic } \\
\text { journals or books } \\
\text { (SA3) It is important that students become familiar with online collaborative } \\
\text { environments }\end{array}$ \\
\hline Social image & $\begin{array}{l}\text { (IM1) The use of Wikipedia is well considered among colleagues } \\
\text { (IM2) My colleagues use Wikipedia }\end{array}$ \\
\hline Profile 2.0 & $\begin{array}{l}\text { (PF1) I contribute to blogs } \\
\text { (PF2) I actively participate in social networks } \\
\text { (PF3) I publish academic content in open platforms }\end{array}$ \\
\hline Quality & $\begin{array}{l}\text { (QU1) Articles in Wikipedia are reliable } \\
\text { (QU2) Articles in Wikipedia are updated } \\
\text { (QU3) Articles in Wikipedia are comprehensive }\end{array}$ \\
\hline Perceived enjoyment & $\begin{array}{l}\text { (ENJ1) The use of Wikipedia stimulates curiosity } \\
\text { (ENJ2) The use of Wikipedia is entertaining }\end{array}$ \\
\hline Perceived usefulness & $\begin{array}{l}\text { (PU1) The use of Wikipedia makes it easier for students to develop new skills } \\
\text { (PU2) The use of Wikipedia improves student's learning } \\
\text { (PU3) Wikipedia is useful for teaching }\end{array}$ \\
\hline Perceived ease of use & $\begin{array}{l}\text { (PEOU1) Wikipedia is user-friendly } \\
\text { (PEOU2) It is easy to find in Wikipedia the information you seek }\end{array}$ \\
\hline Behavioral intention & $\begin{array}{l}\text { (BI1) In the future I will recommend the use of Wikipedia to my colleagues and } \\
\text { students } \\
\text { (BI2) In the future I will use Wikipedia in my teaching activity }\end{array}$ \\
\hline Use behavior & $\begin{array}{l}\text { (USE1) I use Wikipedia to develop my teaching materials } \\
\text { (USE2) I use Wikipedia as a platform to develop educational activities with students } \\
\text { (USE3) I recommend my students to use Wikipedia } \\
\text { (USE4) I recommend my colleagues to use Wikipedia }\end{array}$ \\
\hline
\end{tabular}

\section{Results}

The model was studied through Structural Equation Modeling (SEM), and the estimation was implemented considering maximum likelihood. After checking the reliability and validity of the research instruments, we have tested the initial hypothesis (see Figure 1) by conducting a SEM analysis.

\section{Measurement model}

The internal reliability of the constructs in the model was checked through the Cronbach $\alpha$ and item-to-total correlations. Table 2 shows that all Cronbach's $\alpha$ values for all constructs are above the minimum value of 0.7 (Cronbach, 1947), except in the case of the construct "Perceived ease of use". Nevertheless, taking into account that it is very close to the lower bound, we can consider it as acceptable. Concerning the item-to-total correlation, we have the same situation. Although all values are above 0.60 , the recommended level for field studies (Ahn, Ryu, \& Han, 2007), we have several constructs where some of the items have the item- 
to-total correlation lower than this value. Again, taking into account that they are very close to the requested bound, and the fact that we are in the framework of a field study, we will consider that from the internal point of view, the constructs can be considered adequate.

Table 2: Internal reliability, convergent validity and discriminant validity of the constructs.

\begin{tabular}{|c|c|c|c|c|c|c|c|c|}
\hline \multirow[b]{2}{*}{ Construct } & \multirow[b]{2}{*}{ Variable } & \multicolumn{2}{|c|}{ Internal reliability } & \multicolumn{3}{|c|}{ Convergent validity } & \multicolumn{2}{|c|}{$\begin{array}{c}\text { Discriminant } \\
\text { validity }\end{array}$} \\
\hline & & $\begin{array}{l}\text { Cronbach's } \\
\text { alpha }\end{array}$ & $\begin{array}{l}\text { Item-total } \\
\text { correlation }\end{array}$ & $\begin{array}{l}\text { Factor } \\
\text { loading }\end{array}$ & CR & AVE & MSV & ASV \\
\hline \multirow[t]{2}{*}{ Job relevance } & JR1 & 0.776 & 0.634 & 0.904 & 0.778 & 0.638 & 0.099 & 0.053 \\
\hline & $J R 2$ & & 0.634 & 0.904 & & & & \\
\hline \multirow[t]{3}{*}{ Sharing attitude } & SA1 & 0.838 & 0.714 & 0.877 & 0.842 & 0.639 & 0.263 & 0.133 \\
\hline & $\mathrm{SA} 2$ & & 0.694 & 0.864 & & & & \\
\hline & SA3 & & 0.706 & 0.873 & & & & \\
\hline \multirow[t]{2}{*}{ Social image } & IM1 & 0.735 & 0.581 & 0.889 & 0.736 & 0.583 & 0.440 & 0.203 \\
\hline & IM2 & & 0.581 & 0.889 & & & & \\
\hline \multirow[t]{3}{*}{ Profile 2.0} & PF1 & 0.794 & 0.645 & 0.847 & 0.795 & 0.563 & 0.180 & 0.081 \\
\hline & PF2 & & 0.642 & 0.845 & & & & \\
\hline & PF3 & & 0.621 & 0.832 & & & & \\
\hline \multirow[t]{3}{*}{ Quality } & QU1 & 0.842 & 0.740 & 0.892 & 0.845 & 0.646 & 0.376 & 0.207 \\
\hline & QU2 & & 0.735 & 0.889 & & & & \\
\hline & QU3 & & 0.648 & 0.835 & & & & \\
\hline \multirow[t]{2}{*}{ Perceived enjoyment } & ENJ1 & 0.732 & 0.581 & 0.889 & 0.736 & 0.582 & 0.518 & 0.208 \\
\hline & ENJ2 & & 0.581 & 0.889 & & & & \\
\hline \multirow[t]{3}{*}{ Perceived usefulness } & PU1 & 0.864 & 0.756 & 0.895 & 0.864 & 0.680 & 0.546 & 0.286 \\
\hline & PU2 & & 0.756 & 0.895 & & & & \\
\hline & PU3 & & 0.714 & 0.871 & & & & \\
\hline \multirow[t]{2}{*}{ Perceived ease of use } & PEOU1 & 0.653 & 0.566 & 0.856 & 0.683 & 0.469 & 0.518 & 0.152 \\
\hline & PEOU2 & & 0.566 & 0.856 & & & & \\
\hline \multirow[t]{2}{*}{ Behavioral intention } & BI1 & 0.916 & 0.845 & 0.961 & 0.916 & 0.845 & 0.679 & 0.289 \\
\hline & $\mathrm{B} 12$ & & 0.845 & 0.961 & & & & \\
\hline \multirow[t]{4}{*}{ Use behavior } & USE1 & 0.865 & 0.701 & 0.833 & 0.867 & 0.627 & 0.679 & 0.261 \\
\hline & USE2 & & 0.596 & 0.753 & & & & \\
\hline & USE3 & & 0.801 & 0.902 & & & & \\
\hline & USE4 & & 0.770 & 0.882 & & & & \\
\hline
\end{tabular}

Regarding convergent validity, factor loadings exceed the recommended value of 0.60 (Ahn et al., 2007). By performing a Confirmatory Factor Analysis (CFA) involving all constructs of the model, we have obtained the composite reliability (CR) and the average variance extracted (AVE). It can be checked in Table 1 that CR is greater than the recommended value of 0.70 in all cases (Hair, Black, Babin, \& Anderson, 2010), except in the case of the construct "Perceived ease of use". Nevertheless, taking into account that it is very close to the lower bound, we can consider it as acceptable. Concerning AVE, we have a similar situation. It is greater than the recommended lower bound of 0.50 (Hair et al., 2010) in all cases except in one: the construct "Perceived ease of use". Nevertheless, since its value is pretty close to this bound, we do accept that convergent validity is also accomplished in this case. Besides, in all cases (including "Perceived ease of use") the condition is satisfied that CR is greater than AVE, which in turn is another desirable condition regarding the convergent validity (Hair et al., 2010). 
The comparison between the Maximum Shared Squared Variance (MSV) and the Average Shared Squared Variance (ASV) of a construct (with respect to all the other constructs) with the corresponding AVE, shows the discriminant validity of the constructs (Hair et al., 2010). In most cases, AVE is clearly greater than MSV and ASV (see Table 1). Although constructs "Perceived ease of use" and "Use behavior" do not satisfy this condition, we see that the values are quite similar. Hence, taking into account the importance of these constructs in the theoretical model we have built, we do also accept their discriminant validity.

\section{Structural model}

Since the research measures are reliable and valid, we can proceed to check the goodness of fit of our path model (see Table 3). Initially, the $\chi^{2}$ test indicates that our model does not have a good fit ( $p$-value $=0.000$ ). But we have to bear in mind that the $\chi^{2}$ statistic heavily depends on the sample size, and in the case of large samples the test almost always tends to dismiss the model (Bentler \& Bonett, 1980; Jöreskog \& Sörbom, 1993). Since our sample size is 8 times the minimum recommended sample size of 100 (Gorsuch, 1983 \& Kline, 1979), we have to consider other fit indexes. For example, the $\chi^{2} /$ d.f. fit index shows a good fit of the model since it is lower than the upper bound of 5.00 (Marsh \& Hocevar, 1985), as shown in Table 3.

Table 3: Fit indexes of the structural model.

\begin{tabular}{lcc}
\hline Fit index & Value & $\begin{array}{c}\text { Recommended } \\
\text { cut-off values }\end{array}$ \\
\hline Absolute fit measures & 1164.594 & The lower the better \\
Minimum fit function chi-square ( $\chi^{2}$ ) & 283 & \\
Degrees of freedom (d.f.) & 0.000 & $>0.050$ \\
P-value & 4.115 & $<5.000$ \\
$\chi^{2} /$ d.f. & 0.895 & $>0.800$ \\
Goodness-of-fit index (GFI) & 0.075 & $<0.080$ \\
Standardized root mean square residual (SRMR) & 0.062 & $<0.080$ \\
Root mean square error of approximation (RMSEA) & & $>0.800$ \\
Incremental fit measures & 0.870 & $>0.900$ \\
Adjusted goodness-of-fit index (AGFI) & 0.910 & $>0.900$ \\
Tucker-Lewis index (TLI) or (NNFI) & 0.899 & $>0.900$ \\
Normed fit index (NFI) & 0.921 & $>0.500$ \\
Comparative fit index (CFI) & & $>0.500$ \\
Parsimonious fit measures & 0.722 & $>0.500$ \\
Parsimonious goodness of fit index (PGFI) & 0.783 & \\
Parsimonious normed fit index (PNFI) & 0.802 & \\
Parsimonious comparative fit index (PCFI) & & \\
\hline
\end{tabular}

The goodness of fit index (GFI) is greater than the recommended value of 0.80 (Subhash, 1996). We get that $89.50 \%$ of the variance is explained by the model. If we adjust this fit index to the number of parameters in the model (AGFI) and to the number of paths in the model (PGFI), we also obtain two good fit measures since they are greater than the minimum acceptable values of 0.90 (Subhash, 1996) and 0.50 (Mulaik, James, Van Alstine, Bennett, Lind, \& Stilwell, 1989), respectively. 
Continuing with the absolute fit measures of the model, we have that the standardized root mean square residual (SRMR) is lower than the recommended upper bound of 0.08 (Byrne, 1998; Diamantopoulos \& Siguaw, 2000). Furthermore, the root mean square error of approximation (RMSEA) shows that the model explains the population's covariance matrix very well. It is clearly lower than the recommended cut-off value of 0.08 (MacCallum, Browne, \& Sugawara, 1996).

To compare our proposed model with the null model, where there are no links between variables, we have to analyze some incremental fit measures. The normed fit index (NFI), that measures the difference between the $\chi^{2}$ of the null model and the estimated model, does not exceed the minimum required value of 0.90 (Hu \& Jen, 2005). Although its value is just 0.001 below, we do consider it as an acceptable fit result. Additionally, two other incremental fit measures, the Tucker-Lewis index (TLI) and the comparative fit index (CFI), are both greater than the acceptable lower bound of 0.90 (Hu \& Jen, 2005, and Bentler, 1990, respectively).

Finally, there are two additional parsimonious fit measures worth noting. Both the parsimonious normed fit index (PNFI) and parsimonious comparative fit index (PCFI) indicate a good fit of the model since they are greater than 0.50 (Mulaik et al, 1989).

Since the great majority of fit indexes are good, we consider that our proposed structural model is deemed adequate to explain the relationships between variables and to test the associated hypotheses. The analysis of the parameters estimation will allow us to validate the statements in those hypotheses. Table 4 shows that the values of the regression weights between constructs are positive and significantly different from zero $(\alpha=0.05)$. Consequently, all the hypothesized links established in this research work are supported: "Job relevance" has a positive and significant impact on "Social image" $(\beta=0.26, p<0.01)$; likewise, "Social image" has a direct effect on "Quality of Wikipedia" $(\beta=0.55, p<0.01)$, "Sharing attitude" $(\beta=0.23, p$ $<0.01$ ), "Profile 2.0" ( $\beta=0.29, p<0.01)$, "Perceived usefulness" $(\beta=0.43, p<0.01)$ and "Behavioral intention of use" $(\beta=0.42, p<0.01)$; and "Quality of Wikipedia" positively influences "Perceived enjoyment" $(\beta=0.52, p<0.01)$ and "Perceived usefulness" $(\beta=0.35, p<$ $0.01)$. Consistent with our hypotheses, "Job relevance" has a positive and significant impact on "Sharing attitude" $(\beta=0.21, p<0.01)$. And "Sharing attitude" influences "Profile 2.0" $(\beta=0.41$, $p<0.01)$ and "Behavioral intention of use" $(\beta=0.13, p<0.01)$. Besides "Perceived enjoyment" positively affects "Perceived ease of use" $(\beta=0.53, p<0.01)$. It is also influenced by "Profile 2.0 " $(\beta=0.11, p<0.01)$. For its part, "Perceived ease of use" has a direct impact on "Perceived usefulness" ( $\beta=0.44, p<0.01$ ). Finally, "Perceived usefulness" has a significant impact on "Behavioral intention of use" $(\beta=0.60, p<0.01)$, and this in turn positively affects "Use behavior" $(\beta=0.68, p<0.01)$.

Table 4: Hypothesis and structural model path coefficients.

\begin{tabular}{clllcccc}
\hline Hypothesis & & & & Estimate & S.E. & \multicolumn{1}{c}{ C.R. } & P \\
\hline H1 & Behavioral_intention & $\rightarrow$ & Use_behavior & 0.683 & 0.033 & 20.455 & 0.000 \\
H2a & Sharing_attitude & $\rightarrow$ & Behavioral_intention & 0.128 & 0.040 & 3.214 & 0.001 \\
H2b & Social image & $\rightarrow$ & Behavioral_intention & 0.416 & 0.060 & 6.885 & 0.000 \\
H2c & Perceived_usefulness & $\rightarrow$ & Behavioral_intention & 0.601 & 0.048 & 12.604 & 0.000 \\
H3a & Quality & $\rightarrow$ & Perceived_usefulness & 0.353 & 0.055 & 6.422 & 0.000 \\
H3b & Social image & $\rightarrow$ & Perceived_usefulness & 0.427 & 0.058 & 7.347 & 0.000 \\
H3c & Profile2.0 & $\rightarrow$ & Perceived_usefulness & 0.105 & 0.030 & 3.461 & 0.000 \\
H3d & Perceived_ease & $\rightarrow$ & Perceived_usefulness & 0.436 & 0.073 & 5.944 & 0.000
\end{tabular}




\begin{tabular}{llllllll} 
H4 & Perceived_enjoyment & $\rightarrow$ & Perceived_ease & 0.534 & 0.047 & 11.395 & 0.000 \\
H5 & Quality & $\rightarrow$ & Perceived_enjoyment & 0.516 & 0.043 & 11.907 & 0.000 \\
H6 & Social image & $\rightarrow$ & Quality & 0.554 & 0.047 & 11.714 & 0.000 \\
H7a & Sharing_attitude & $\rightarrow$ & Profile2.0 & 0.405 & 0.064 & 6.290 & 0.000 \\
H7b & Social image & $\rightarrow$ & Profile2.0 & 0.292 & 0.065 & 4.523 & 0.000 \\
H8a & Job_relevance & $\rightarrow$ & Sharing_attitude & 0.210 & 0.037 & 5.729 & 0.000 \\
H8b & Social image & $\rightarrow$ & Sharing_attitude & 0.229 & 0.045 & 5.131 & 0.000 \\
H9 & Job_relevance & $\rightarrow$ & Social image & 0.257 & 0.039 & 6.561 & 0.000 \\
\hline
\end{tabular}

\section{Discussion}

As our model shows in the results of the estimation, all hypothesized links are active within the internal factors of the model. Behavioral intention to use Wikipedia: (H1) influences Wikipedia's effective use behavior; $(\mathrm{H} 2 \mathrm{c})$ perceived usefulness of Wikipedia affects behavioral intention to use Wikipedia; and ( $\mathrm{H} 3 \mathrm{~d}$ ) perceived ease of use of Wikipedia has a positive impact on the perceived usefulness of Wikipedia. These relationships are unsurprising as they have been studied in Venkatesh \& Bala (2008), but our paper offers proof that the relationships have additional validity within the Wikipedia framework and its academic use in Higher Education.

We find a strong positive perception of Wikipedia's quality among faculty members that is not found in earlier studies such as Jaschik (2007) and Dooley (2010). In principle, at the very least, this favorable perspective should spur on the use of Wikipedia for academia purposes. Our results highlight that quality perception positively influences perceived enjoyment (H5) and the perceived use of Wikipedia ( $\mathrm{H} 3 \mathrm{a}$ ). So the perception of quality has an indirect impact on the eventual decision to make use of Wikipedia as part of the teaching process.

"Quality" is presented in academic literature as the main issue that explains faculty attitudes and practices towards Wikipedia (Chen, 2010). But we have found other external factors that are key characters in explaining Wikipedia's use for teaching purposes. These factors come back to Wikipedia's social image within academia, and faculty attitudes towards: (a) publishing open resources, and; (b) encouraging students to familiarize themselves with collaborative environments. Both of these external factors have a direct effect on behavioral intention to use Wikipedia ( $\mathrm{H} 2 \mathrm{a}$ and $\mathrm{H} 2 \mathrm{~b}$ ). In addition, as many as five of the ten constructs in our model are influenced by the social environment $(\mathrm{H} 2 \mathrm{~b}, \mathrm{H} 3 \mathrm{~b}, \mathrm{H} 6, \mathrm{H} 7 \mathrm{~b}$, and $\mathrm{H} 8 \mathrm{~b})$ - and our proof of the social environment's direct effect on the perception of quality (H6) is of specific importance. This was unexpected. But few studies analyze how the perception of quality is specifically built. Consequently, it is an important contribution to the existing literature.

With respect to the remaining (external) factors, we need to mention the significant influence of the institutional recognition and support that faculty receive from their university when open platforms like Wikipedia are employed. Like Bayliss (2013) has shown, we demonstrate that academic use of Wikipedia will be facilitated by more positive institutional support toward collaborative knowledge production in academic settings. All of the other variables in the model are indirectly affected by this construct, and two important factors - "Sharing attitude" and "Image" (H8a and H9) - are directly affected. 


\section{Conclusions}

In this paper we describe the main factors influencing the teaching uses of Wikipedia among university faculty, and the direct effects between them. Based on the extended TAM model, we consider two types of factors. On one hand we introduced the internal constructs of the TAM model (perceived ease of use of Wikipedia, perceived usefulness of Wikipedia, behavioral intention to use Wikipedia, and Wikipedia use behavior) in our model. On the other hand we consider the following six external factors, which can be considered as antecedents of the four internal factors: Job relevance, Sharing attitude, Social image, Profile 2.0, Quality of Wikipedia, and Perceived enjoyment.

We studied the model through Structural Equation Modeling (SEM), using data from an online survey that was conducted throughout all faculty members of the Universitat Oberta de Catalunya. After checking the reliability and the validity of the research instruments, we have estimated the model and we have found that all initial hypotheses were supported.

The results analyzed in the Discussion Section indicate that the perception of colleagues' opinion about Wikipedia and the perceived quality of the information on Wikipedia play a central role in our model. Though previous studies had already emphasized quality concerns as one of the main determinants for faculty practices and attitudes about Wikipedia, colleagues' views were not considered particularly important. Our model supports a remarkable influence of colleagues' perceived opinion on the quality assessment of Wikipedia articles: the more one thinks colleagues share a positive view, the more articles are perceived to be of better quality and the more Wikipedia is found to be useful. Usefulness is in fact directly conditioned both by quality perception and by the social image it is believed to have. Finally, colleagues' opinions are also directly affecting the intention to use Wikipedia for teaching purposes. All in all, colleagues seem to act as strong role models for most faculty members on this issue, which may also be a consequence of the resilient peer culture within academia and science.

The existence of institutional support initiatives concerning the use of open collaborative environments is also another important factor in our model. It has got a significant directed impact on the perceived usefulness of Wikipedia which, in turn, affects the behavioral intention of using Wikipedia. The lack of formal incentives might also explain the low amount of active contributions to Wikipedia, editing, by faculty members, since most standard systems for research assessment do not take publications in open platforms like this into account.

Nevertheless, despite the lack of institutional support and acknowledgement, a growing number of academics think it is very useful and desirable to publish research results or even intermediate data in open repositories. In that sense our model also highlights both the degree to which an individual considers it is important to participate in open collaborative environments and his/her profile 2.0, as two other crucial factors. What we have called the "sharing attitude" has a direct effect on profile 2.0 and on the behavioral intention of using Wikipedia for teaching purposes.

All these findings may be used to suggest some practical recommendations, both for academic institutions and for individual faculty members. For universities and other academic institutions willing to encourage (for teaching purposes) the use of collaborative environments among their members it will be useful to explicitly acknowledge these kinds of practices as an important element in assessing teaching skills and innovation. It would be particularly valuable 
to recognize in a more formal manner the efforts of those faculty members who use these collaborative platforms combined with open resources of information, like Wikipedia.

Second, although specific training courses organized by instructional designers might indeed be useful, our results show that faculty members are particularly sensitive to their colleagues' own experiences and insights. Therefore, what could be more effective are training materials that gather actual best practices or training sessions delivered by other faculty members with some previous expertise in the matter. Training sessions or specific courses may include teaching uses of Wikipedia within broader issues on collaborative environments, other web 2.0 tools and open educational resources, since these factors were found to be very influential in our study.

For those faculty members already using Wikipedia as a learning tool, we think it would have greater impact if they publically acknowledged their practices more, especially to their close colleagues, and explain their own teaching experiences as well as the effects it has had on the students' academic performance. Documenting those practices (in academic papers, reports or presentations) is also another laudable strategy that serves the same purpose.

Although respondents came from a variety of backgrounds and disciplines, data was collected at only one institution. This limitation of the research developed in this paper offer opportunities for future investigations. Further research should include the perceptions of faculty members from a wide range of Universities, across blended and pure-online models.

\section{Acknowledgment}

The authors would like to thank the Universitat Oberta de Catalunya for their kind permission to conduct the survey to all their faculty members. This research has been funded by a grant from the Recercaixa Programme 2011 (Associació Catalana d'Universitats Públiques-LaCaixa).

\section{References}

Ahn, T., Ryu, S., \& Han, I. (2007). The impact of web quality and playfulness on user acceptance of online retailing. Information and Management, 44(3), 263-275.

Alonso, M.I., \& García, J. (2013). Colaboración activa en Wikipedia como método de aprendizaje. Revista Iberoamericana de Educación a Distancia, 16(1), 13-26.

An, Y.-J., \& Williams, K. (2010). Teaching with Web 2.0 technologies: benefits, barriers and lessons learned. International Journal of Instructional Technology \& Distance Learning, 7(3), 41-58.

Bagozzi, R.P., Davis, F.D., \& Warshaw, P.R. (1992). Development and test of a theory of technological learning and usage. Human Relations, 45(7), 659-686.

Bayliss, G. (2013). Exploring the cautionary attitude toward Wikipedia in higher education: implications for higher education institutions. New Review of Academic Librarianship, 19(1), 36-57. 
Bentler, P.M. (1990). Comparative fit indexes in structural models. Psychological Bulletin, 107(2), 238-246.

Bentler, P.M., \& Bonett, D.G. (1980). Significance tests and goodness of fit in the analysis of covariance structures. Psychological Bulletin, 88(3), 588-606.

Black, E.W. (2008). Wikipedia and academic peer-review: Wikipedia as a recognized medium for scholarly publication?. Online Information Review, 32(1), 73-88.

Brox, H. (2012). The elephant in the room: a place for Wikipedia in higher education?. Nordlit, 30, 143-155.

Byrne, B.M. (1998). Structural equation modeling with LISREL, PRELIS and SIMPLIS: basic concepts, applications and programming. Mahwah, New Jersey: Lawrence Erlbaum Associates.

Chen, H.-L. (2010). The perspectives of higher education faculty on Wikipedia. The Electronic Library, 28(3), 361-373.

Chen, S.-L. (2010). Wikipedia: a republic of science democratized. Albany Law Journal of Science and Technology, 20(2), 247-325.

Chen, S.-C., Chen, H.-H., \& Chen, M.-F. (2009). Determinants of Satisfaction and Continuance Intention towards Self-service Technologies. Industrial Management \& Data Systems, 109(9), 1248-1263.

Chuttur M.Y. (2009). Overview of the Technology Acceptance Model: origins, developments and future directions. Indiana University, USA. Working Papers on Information Systems, 9(37).

Cronbach, L. (1947). Test "reliability": its meaning and determination. Psychometrica, 12(1), 116.

Diamantopoulos, A., \& Siguaw, J.A. (2000). Introducing LISREL: a guide for the uninitiated. London: Sage Publications.

Dooley, P.L. (2010). Wikipedia and the two-faced professoriate. In Proceedings of the $16^{\text {th }}$ International Symposium on Wikis and Open Collaboration (Wikisym'10). New York: ACM.

Eijkman, H. (2010). Academics and Wikipedia: reframing Web 2.0+ as a disruptor of traditional academic power-knowledge arrangements. Campus-Wide Information Systems, 27(3), 173-185.

Godoe, P., \& Johansen, T.S. (2012). Understanding adoption of new technologies: Technology readiness and technology acceptance as an integrated concept. Journal of European Psychology Students, 3, 38-52.

Gorsuch, R.L. (1983). Factor analysis. Hillsdale, NJ: Lawrence Erlbaum Associates.

Hair, J.F., Black, W.C., Babin, B.J., \& Anderson, R.E. (2010). Multivariate data analysis. Upper Saddle River, NJ: Prentice-Hall.

Hu, K.C., \& Jen, W. (2005). Applications of LISREL and neural network to analyze the passenger's behavioral intention. Logistics Research Review, 8, 43-55. 
Jaschik, S. (2007, January 26). A stand against Wikipedia. Inside Higher Ed. Retrieved from http://www.insidehighered.com

Jöreskog, K., \& Sörbom, D. (1993). LISREL 8: structural equation modeling with the SIMPLIS Command Language. Lincolnwood, IL: Scientific Software International.

King, W.R., \& He, J. (2006). A meta-analysis of the technology acceptance model. Information \& Management, 43(6), 740-755.

Kline, P. (1979). Psychometrics and psychology. London: Academic Press.

Knight, C., \& Pryke, S. (2012). Wikipedia and the university, a case study. Teaching in Higher Education, 17(6), 649-659.

Lee, M.-C. (2009). Factors influencing the adoption of internet banking: An integration of TAM and TPB with perceived risk and perceived benefit. Electronic Commerce Research and Applications, 8(3), 130-141.

Lee, Y., Kozar, K.A., \& Larsen, K.R.T. (2003). The Technology Acceptance Model: Past, Present, and Future. Communications of the Association for Information Systems, 12, Article $50,752-780$.

Lim, S. (2009). How and why do college students use Wikipedia?. Journal of the American Society for Information Science and Technology, 60(11), 2189-2202.

Lin, C.H., Shih, H.Y., \& Sher, P.J. (2007). Integrating technology readiness into technology acceptance: The TRAM model. Psychology \& Marketing, 24(7), 641-657.

MacCallum, R.C., Browne, M.W., \& Sugawara, H.M. (1996). Power analysis and determination of sample size for covariance structure modeling. Psychological Methods, 1(2), 130-149.

Marsh, H.W., \& Hocevar, D. (1985). Application of confirmatory factor analysis to the study of self-concept: First- and higher order factor models and their invariance across groups. Psychological Bulletin, 97(3), 562-582.

Mulaik, S.A., James, L.R., Van Alstine, J., Bennett, N., Lind, S., \& Stilwell, C.D. (1989). Evaluation of goodness-of-fit indices for structural equation models. Psychological Bulletin, 105(3), 430445 .

Subhash, S. (1996). Applied multivariate techniques. New York: John Wiley \& Sons.

Venkatesh, V., \& Bala, H. (2008). Technology acceptance model 3 and a research agenda on interventions. Decision Sciences, 39(2), 273-315.

Venkatesh, V., Morris, M.G., Davis, G.B., \& Davis, F.D. (2003). User acceptance of information technology: toward a unified view. MIS Quarterly, 27(3), 425-478.

Wannemacher, K., \& Schulenburg, F. (2010). Wikipedia in Academic Studies: Corrupting or Improving the Quality of Teaching and Learning?. In Looking Toward the Future of TechnologyEnhanced Education: Ubiquitous Learning and the Digital Native, M. Ebner and M. Schiefner (Eds.) (pp. 295-310). Hershey, PA: IGI Global. 